\title{
ANALYSIS OF THE PROPERTIES OF AW2099 ALUMINIUM-LITHIUM ALLOY WELDED BY LASER BEAM WITH AW5087 ALUMINIUM-MAGNESIUM FILLER MATERIAL
}

\author{
Miroslav Sahul ${ }^{a, *}$, Martin Sahul $^{b}$, Matej PašÁK $^{b}$, Milan MarôneK $^{a}$ \\ a Slovak University of Technology in Bratislava, Faculty of Materials Science and Technology in Trnava, \\ Department of Welding and Joining of Materials, J. Bottu 25, 91724 Trnava, Slovakia \\ ${ }^{b}$ Slovak University of Technology in Bratislava, Faculty of Materials Science and Technology in Trnava, Institute \\ of Materials Science, J. Bottu 25, 91724 Trnava, Slovakia \\ * corresponding author: miroslav.sahul@stuba.sk
}

\begin{abstract}
EN AW2099 aluminium lithium alloy, $2.0 \mathrm{~mm}$ in thickness, was used as an experimental material. EN AW2099 belongs to the $3^{\text {rd }}$ generation of aluminium lithium alloys. The third generation was developed to improve the disadvantages of the previous generation, such as anisotropy in mechanical properties, low fracture toughness, corrosion resistance and resistance to fatigue crack growth, as well. Aluminium magnesium 5087 filler wire with a diameter of $1.2 \mathrm{~mm}$ was used for the welding. Crack free weld joints were produced after an optimization of welding parameters. The microstructure of weld metal and mechanical properties of weld joints were investigated. Equiaxed zone (EQZ) was observed at the fusion boundary. The character of grains changed in the direction towards the weld centre, from the columnar dendrite zone to equiaxed dendrite zone in the weld centre. The microstructure of the weld metal matrix consisted of $\alpha$-aluminium. Alloying elements enrichment was found at the inter-dendritic areas, namely copper and magnesium. The microhardness decrease in the weld metal due to a dissolution of strengthening precipitates was measured. The microhardness was slightly higher in comparison to a weld produced by a laser welding without a filler material. The tensile strength of the weld joint reached around $67 \%$ of the base material's strength and the fracture occurred in the weld metal.
\end{abstract}

Keywords: Aluminium lithium alloy, laser beam welding, equiaxed zone, microstructure, electron microscopy, mechanical properties.

\section{INTRODUCTION}

The main goal in the aerospace industry is to reduce the overall weight of the airplane structure. Aluminium lithium alloys are a promising material from the above mentioned point of view [1]. The application of aluminium lithium alloys is advantageous due to low density, high specific strength, high Young's modulus and increased corrosion resistance [2, 8 . It is known that the addition of $1 \mathrm{wt} . \%$ of lithium could result in the decrease of the alloy density by $3 \%$. Currently, the 3rd generation of aluminium lithium alloys is under development [9]. Important alloys that could be applied in the fuselage's skin stringer components of the newly developed generation are 2099 and 2199 [10]. The 3rd generation is characteristic by a higher $\mathrm{Cu} / \mathrm{Li}$ ratio [11. Many parts of the airplane fuselage are joined by riveting, which is specific for its high cost and low efficiency [12. Thus, it is very important to carry out a research in the field of welding of aluminium lithium alloys. A research focused on welding of Al-Li alloys is a focus of research institutions worldwide. Friction stir welding counts to the joining methods being investigated [13 17]. Investigations are oriented also on welding of aluminium lithium alloys with the use of a filer material. Han et al. conducted double sided laser beam welding with Al-12Si and Al-6.2Cu-5.4Si filler materials. They observed that the application of Al-6.2Cu-5.4Si filler wire resulted in an increase of strength, improvement of hot cracking susceptibility and hoop tensile properties [12. Han et al. investigated the EQZ of laser welds produced with Al-12Si filler material. Authors observed a softening in the EQZ, namely in the local zones enriched by alloying elements [18]. A formation of $\mathrm{T}$ (LiAlSi) and $\theta\left(\mathrm{Al}_{2} \mathrm{Cu}\right)$ and eutectics was observed at the grain boundaries due to segregation [19. Chen et al. similarly performed double sided laser beam welding of 2060-T8 to 2099-T83 aluminium lithium alloy with the use of Al-12Si filler material. Authors found that the EQZ contained dense high-angle grain boundaries. Furthermore, the crack observed during the in-situ tensile testing initiated at the weld toe and then propagated across the partially melted zone and enriched locations of the EQZ [20]. Information on laser beam welding of Al-Li alloys with filler materials of other chemical composition than Al-Si based is still limited. The goal of the paper is to study the microstructure and mechanical properties of EN AW2099 aluminiumlithium alloy laser welds produced with $5087 \mathrm{Al}-\mathrm{Mg}$ based filler material. 


\begin{tabular}{ccccccccccc}
\hline $\mathrm{Cu}$ & $\mathrm{Li}$ & $\mathrm{Zn}$ & $\mathrm{Mg}$ & $\mathrm{Mn}$ & $\mathrm{Zr}$ & $\mathrm{Ti}$ & $\mathrm{Fe}$ & $\mathrm{Si}$ & $\mathrm{Be}$ & $\mathrm{Al}$ \\
\hline $2.4-3.0$ & $1.6-2.0$ & $0.4-1.0$ & $0.1-0.5$ & $0.1-0.5$ & $0.05-0.12$ & $\leq 0.1$ & $\leq 0.07$ & $\leq 0.05$ & $\leq 0.0001$ & Balance \\
\hline
\end{tabular}

TABLE 1. Chemical composition of EN AW2099 Aluminium lithium alloy.

\begin{tabular}{ccccccccccc}
\hline $\mathrm{Si}$ & $\mathrm{Fe}$ & $\mathrm{Cu}$ & $\mathrm{Mg}$ & $\mathrm{Mn}$ & $\mathrm{Cr}$ & $\mathrm{Zn}$ & $\mathrm{Zr}$ & $\mathrm{Ti}$ & $\mathrm{Be}$ & $\mathrm{Al}$ \\
\hline$\leq 0.25$ & $\leq 0.40$ & $\leq 0.05$ & $4.5-5.2$ & $0.7-1.1$ & $0.05-0.25$ & $\leq 0.25$ & $0.1-0.2$ & $\leq 0.15$ & $\leq 0.0003$ & Balance \\
\hline
\end{tabular}

TABle 2. Chemical composition of 5087 filler wire.

\section{EXPERIMENTAL PROCEDURE}

EN AW2099-T83 aluminium lithium alloy was used as the base material. The thickness of the as-delivered Al-Li alloy was $25.4 \mathrm{~mm}$. A solution heat treatment at $530{ }^{\circ} \mathrm{C}$, rapid quenching and cold rolling were carried out. EN AW2099 aluminium lithium alloy was reduced to a thickness of $2 \mathrm{~mm}$. The chemical composition provided by Smiths Metal Centres Ltd. is given in Tab. 1 .

AW 5087 aluminium-magnesium based filler material was used for welding. The diameter of the filler wire was $1.2 \mathrm{~mm}$. The chemical composition of the 5087 filler material is given in Tab. 2. The dimensions of sheets were $2 \times 50 \times 100 \mathrm{~mm}$.

TruDisk 4002 solid state disk laser with the wavelength of $1.03 \mu \mathrm{m}$ was used for the fabrication of weld joints. The beam quality (BPP) was $8 \mathrm{~mm} \cdot \mathrm{mrad}$ and the maximum power of the laser was $2.0 \mathrm{~kW}$. A laser light cable with a diameter of $400 \mu \mathrm{m}$ was used for the transport of the laser light to the focusing optics. Butt weld joints were fabricated. Totally, 20 weld joints were produced. The most proper weld joint was, based on the cross-section evaluation, selected for further analyses. Argon 4.6 with the flow rate of $18 \mathrm{l} / \mathrm{min}$ was utilized as the shielding gas. The welding parameters are the following: laser power $1.5 \mathrm{~kW}$, welding speed $10 \mathrm{~mm} / \mathrm{s}$, focus position $+1 \mathrm{~mm}$ above the sheet surface and filler wire feed rate $1 \mathrm{~m} / \mathrm{min}$. The welding set-up is given in Fig. 1. The angle between the shielding gas supply and horizontal plane was $60^{\circ}$. The filler material was fed under an angle of $25^{\circ}$. The spot size of the laser beam reached $400 \mu \mathrm{m}$. BEO D70 focusing optics was used. The focal length of focusing optics was $200 \mathrm{~mm}$.

The weld joints were prepared by a standard metallographic procedure. Keller's reagent was used to reveal the microstructure of the weld joints. JEOL JSM 7600 F scanning electron microscope was utilized to analyse the microstructure, chemical composition of local zones in weld metal and fracture surfaces after the tensile testing. Vicker's microhardness HV0.1 measurements across weld joint interface in the midthickness of weld cross-section were carried out on Buehler ${ }^{\circledR}$ IndentaMetTM 1100 Series microhardness tester with a loading force of $0.98 \mathrm{~N}$ for $10 \mathrm{~s}$. Tensile properties of weld joints were evaluated with Tinius Olsen 300 ST electromechanical universal testing ma- chine (max. loading force $300 \mathrm{kN}$ ) of Tinius Olsen Company at a crosshead speed of $5 \mathrm{~mm} / \mathrm{s}$.

\section{Results AND DisCUSSION}

The weld bead and weld root appearance of the produced weld joint is given in Fig. 2 The weld bead is regular in width and smooth. No hot cracking was observed in this case. Similarly, the weld root was characteristic by a smooth appearance. The weld width was $4.3 \mathrm{~mm}$. The width of the heat affected zone was $2.2 \mathrm{~mm}$. Because the use of the filler material, no reduction in the cross-sectional area was observed. The measured cross-sectional area was $10.4 \mathrm{~mm}^{2}$. In the case when autogenous welding was carried out, the reduction in the cross section thickness could be usually observed. This could act as a stress concentrator contributing to the decrease in the weld strength.

The microstructure of weld metal - heat affected zone interface is given in Fig. 3 At the fusion boundary, a very narrow EQZ was observed. The EQZ eliminates the growth of epitaxial grains. Lin et al. observed that the width of the EQZ was dependent on the content of lithium and zirconium in filler material [21. The character of the weld metal differs from the morphology point of view. In the direction towards the weld centre, the character of grains changed. A columnar dendritic zone was detected nearby the EQZ. When moving towards the weld centre, equiaxed dendritic zone appeared. This zone consists of fine grains that result from high cooling rates during a laser beam welding and an addition of zirconium present as the alloying element in the filler material. This zone is finer grained as compared to a welding of aluminium lithium alloy without a filler material. Han et al. observed that width of the EQZ was not constant, but changed. The width of the zone of 2060-T8/2099-T83 aluminium-lithium alloys double-side welded by laser beam ranged from 5 to $100 \mu \mathrm{m}$ [18].

The EDS analysis was used for the study of the microstructure in detail. Inter-dendritic locations are marked as Spectrum 1 and 2 (Fig. 4). The higher content of copper was measured due to the segregation. The copper content in Spectrum 1 is 19.6 wt. \% and 19.45 wt. $\%$ in Spectrum 2 (Tab.3). The lower content of aluminium in comparison to Spectrum 3 was recorded in those locations. The aluminium content averaged at $77 \mathrm{wt} . \%$. Furthermore, silicon was 




FiguRE 1. Welding set-up.

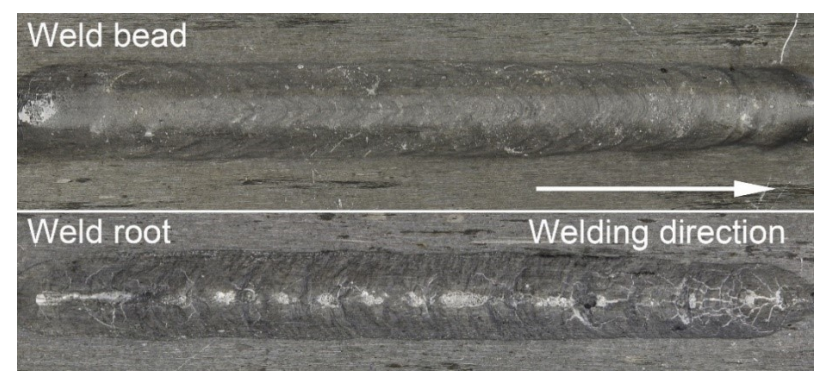

Figure 2. Appearance of weld bead and root surface.

detected. Spectrum 3 is representing the $\alpha$-aluminium solid solution with the content of $97.8 \mathrm{wt} . \%$ of aluminium. No silicon content was detected in the aluminium matrix. The increased amount of magnesium was detected in inter-dendritic areas (Spectrum 1 and 2). The magnesium content was 2.09 and $1.92 \mathrm{wt} . \%$ for Spectrum 1 and 2, respectively. However, Li element is too light to be measured by the EDS analysis.

$\mathrm{Fu}$ et al. observed two kinds of particles in the weld joint on 2A97 aluminium lithium alloy, smaller and larger ones. The larger particles were identified as $\theta^{\prime}$ or T1 [21]. The smaller ones could be $\beta^{\prime}$ or $\alpha^{\prime}$ $\left(\mathrm{Al}_{3}(\mathrm{Li}, \mathrm{Zr})\right)$. Zhang et al. observed an icosahedral quasi crystalline T2 phase in laser welds on 2060 aluminium lithium alloy 22. Han et al. found that the main precipitate found in the EQZ was $\mathrm{T}$ phase (AlLiSi) when AA4047 (Al-12Si) was used as the filler material for double-sided laser beam welding of 2060T8 to 2099-T83. On the other hand, T2 phase was the main precipitate observed in the EQZ of welds produced with the filler material Al-6.2Cu-5.4Si [18.

The increase of microhardness towards the HAZ was observed (Fig. 5). On the contrary, the lowest microhardness values were measured in the weld metal. The average microhardness of the weld metal was 89 HV0.1. The observed microhardness drop is associated to the dissolution of strengthening precipitates and the fact that no heat treatable filler material was used for the joining. However, the average microhardness in the weld metal of the weld produced on EN AW2099 aluminium lithium alloy without a filler material was 72 HV0.1. The higher microhardness for welds made with a filler material is associated with the presence of zirconium in the filler wire causing a grain refinement.

The stress-strain curve of the weld joint on aluminium lithium alloy is given in Fig. 6. A decrease in the weld joint strength was observed. The tensile strength reached the value of $284 \mathrm{MPa}$ being $67 \%$ of the base material's strength (Fig. 7). The tensile strength of the base material was $425 \mathrm{MPa}$. The decrease in mechanical properties of the weld joint is associated with the dissolution of strengthening precipitates. Furthermore, AW5087 filler material was used, which is not precipitation hardenable, thus contributing to the decrease in the weld strength.

Zhang et al. observed that tensile strength of laserbeam welded 2060 Al-Li alloy with 5087 filler wire reached about $63 \%$ of that of the base material [22].

The cross section of the weld joint after the tensile testing is given in Fig. 8 . From the microscopic analysis, it can be deduced that the crack could initiate in the EQZ in the upper part of the weld joint. The fracture is intergranular. Then, the crack propagated towards the columnar dendritic zone at an angle of about $45^{\circ}$ to the tensile loading.

The fracture observed is intergranular with the presence of dimples. Some cracks were also observed (Fig. 9).

The fracture surface was further analysed by EDS analysis. Local chemical composition was measured in locations designed as Spectrums 1 to 3 (Fig. 10). The lighter zones were characterized by a higher content of copper. The copper content was 14.5 and 20 wt. $\%$ for Spectrum 1 and 2, respectively. Furthermore, iron was detected in mentioned locations. In Spectrum 3, the surface EDS analysis was carried out. The content of aluminium was higher in this case, i.e. $87.5 \mathrm{wt} \%$. On the contrary, a copper content decrease to 9 wt. $\%$ was recorded.

The results of the analysis of the fracture's surface chemical composition are given in Tab. 4.

\section{Conclusions}

A characterization of the microstructure and mechanical properties of a disk-laser beam-welded EN AW2099 Aluminium lithium alloy with the use of 5087 filler material was carried out within the study. The major conclusions are as follows:

- equiaxed zone was observed at the fusion boundary - weld metal interface,

- In the direction towards the weld centre, the character of grains changed. A columnar dendritic zone was detected nearby the equiaxed zone. Fine equiaxed dendrites were also detected in the weld centre,

- inter-dendritic locations were enriched in alloying elements, i.e. copper and magnesium due to a segregation, 




Figure 3. Microstructure of a) weld metal - HAZ interface, b) dendritic zone in the weld centre.

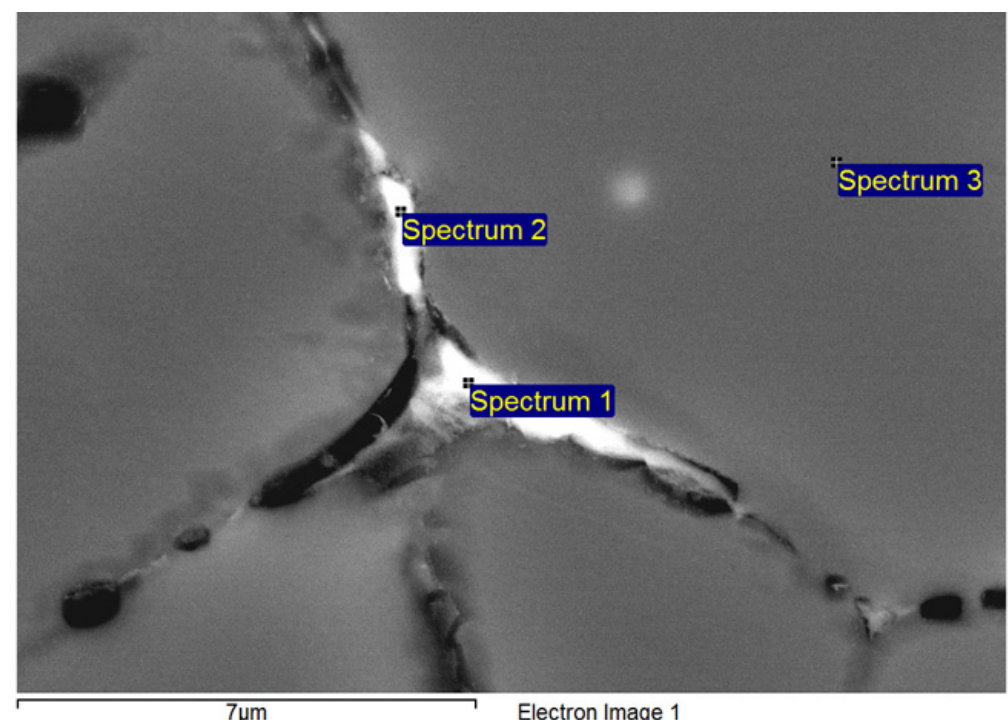

FIGURE 4. EDS point analysis of weld metal.

\begin{tabular}{ccccccc}
\hline Spectrum & $\mathrm{Mg}$ & $\mathrm{Al}$ & $\mathrm{Si}$ & $\mathrm{Mn}$ & $\mathrm{Cu}$ & $\mathrm{Zn}$ \\
\hline 1 & 2.09 & 77.18 & 0.26 & 0.31 & 19.60 & 0.56 \\
2 & 1.92 & 77.34 & 0.49 & 0.23 & 19.45 & 0.56 \\
3 & 0.58 & 97.75 & - & 0.41 & 0.86 & 0.41 \\
\hline
\end{tabular}

TABLE 3. EDS analysis of inter-dendritic areas (in wt. \%).

\begin{tabular}{ccccccc}
\hline Spectrum & $\mathrm{Mg}$ & $\mathrm{Al}$ & $\mathrm{Si}$ & $\mathrm{Mn}$ & $\mathrm{Fe}$ & $\mathrm{Cu}$ \\
\hline 1 & 1.12 & 66.93 & 0.46 & 6.21 & 10.82 & 14.46 \\
2 & 2.26 & 67.44 & 0.32 & 2.84 & 7.16 & 19.99 \\
3 & 2.82 & 87.52 & 0.24 & 0.29 & - & 9.12 \\
\hline
\end{tabular}

TABLE 4. EDS analysis of fracture surface results (in wt. \%). 


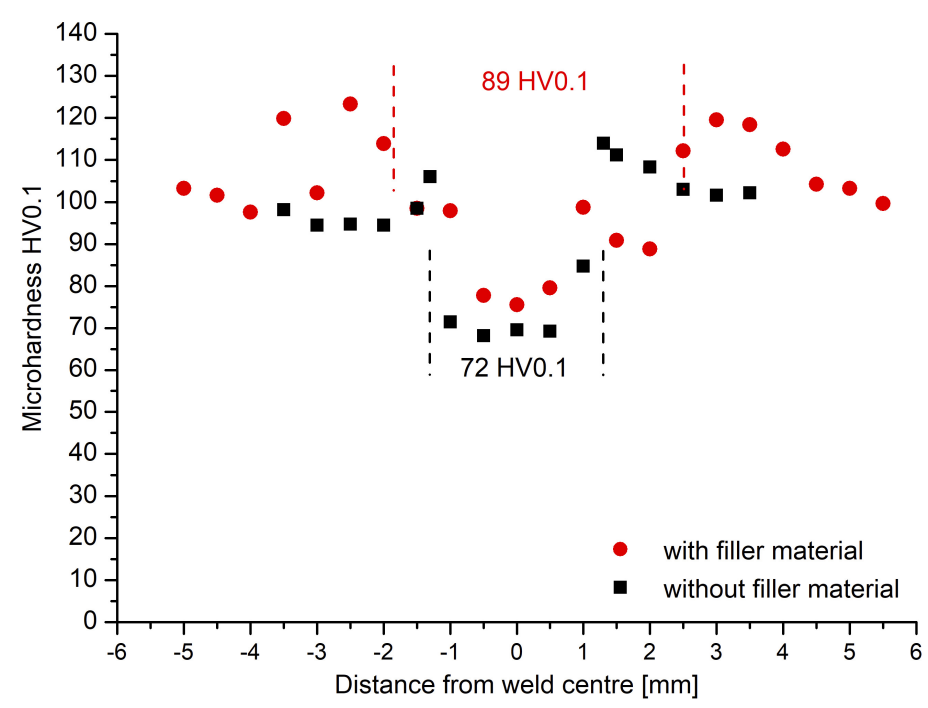

Figure 5. Course of microhadness HV0.1 across base material - HAZ - weld metal interface.

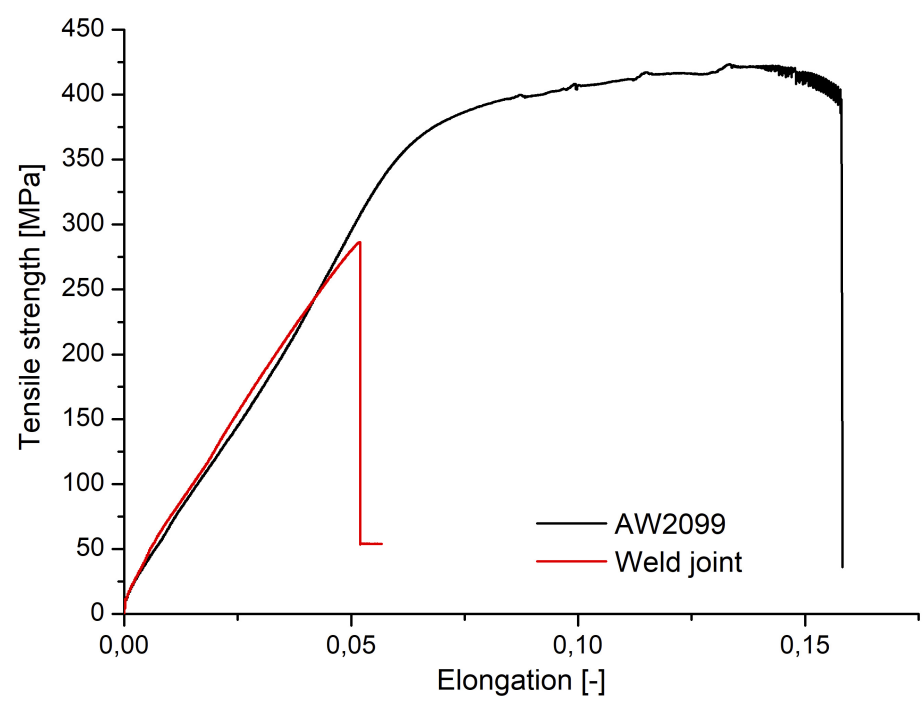

Figure 6. Stress - strain curve of EN AW2099 weld joint.

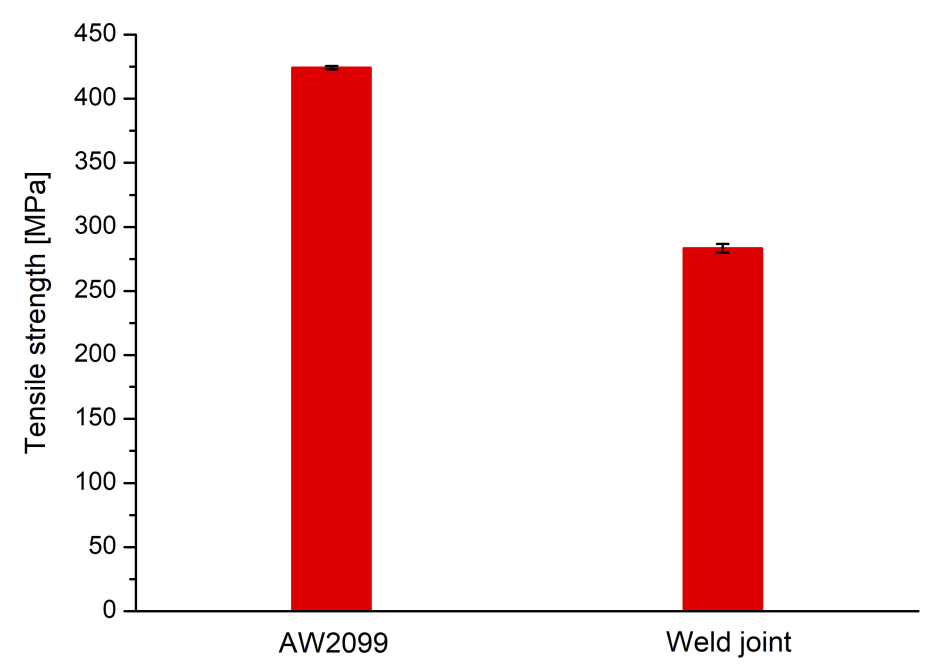

FIgURE 7. Tensile strength of EN AW2099 aluminium lithium alloy and the weld joint produced with the Al-Mg filler material. 



Figure 8. Cross section of weld joint after tensile testing, b) detail of the crack initiation zone.


Figure 9. Fracture surfaces after tensile testing of weld joint.

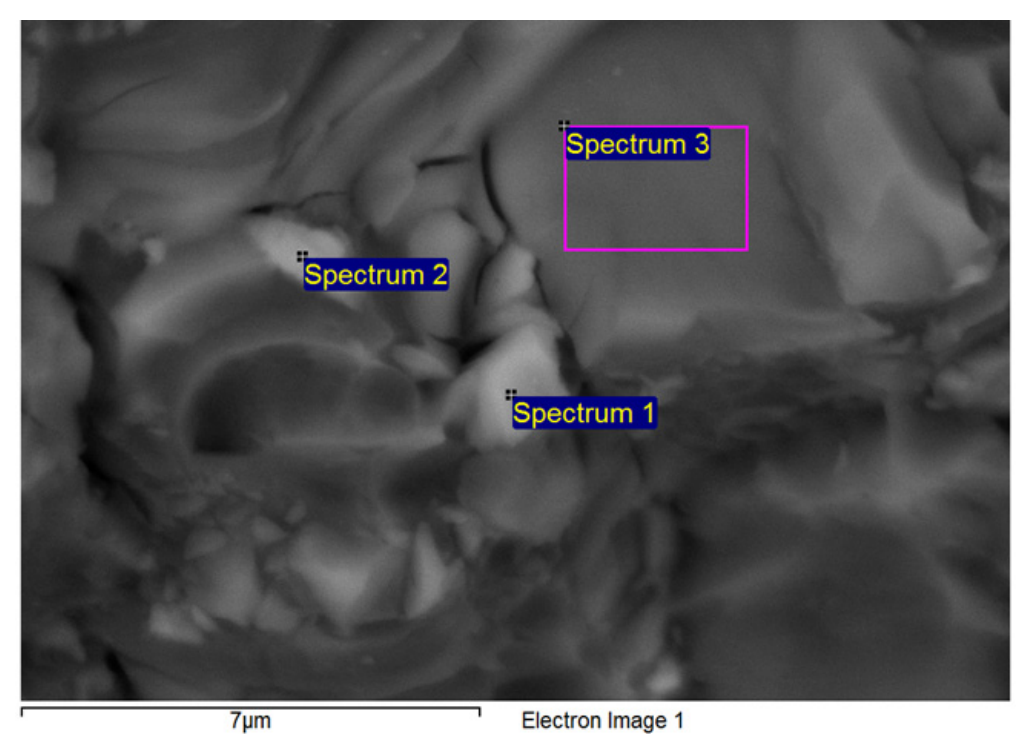

FIGURE 10. EDS point analysis of the fracture surface. 
- the tensile strength of the weld joint reached $284 \mathrm{MPa}$, being around $67 \%$ of the base material's strength, i.e. $425 \mathrm{MPa}$ and a fracture occurred in the weld metal,

- the lowest microhardness values were measured in the weld metal ( 89 HV0.1 for a weld joint produced with 5087 filler material and 72 HV0.1 for a weld produced without the use of a filler material) due to a dissolution of precipitates.

\section{ACKNOWLEDGEMENTS}

This work was supported by the Slovak Research and Development Agency under the contract No. APVV-150337 .

\section{REFERENCES}

[1] A. Malikov, A. Orishich, A. Golyshev, E. Karpov. Manufacturing of high-strength laser welded joints of an industrial aluminum alloy of system $\mathrm{Al}-\mathrm{Cu}-\mathrm{Li}$ by means of post heat treatment. Journal of Manufacturing Processes 41:101 - 110, 2019. DOI:10.1016/j.jmapro.2019.03.037

[2] R. Xiao, X. Zhang. Problems and issues in laser beam welding of aluminum-lithium alloys. Journal of Manufacturing Processes 16(2):166 - 175, 2014. DOI:10.1016/j.jmapro.2013.10.005

[3] C. Gao, R. Gao, Y. Ma. Microstructure and mechanical properties of friction spot welding aluminium-lithium 2A97 alloy. Materials $\& 5$ Design 83:719 - 727, 2015. DOI:10.1016/j.matdes.2015.06.013.

[4] J. Entringer, M. Reimann, A. Norman, J. F. dos Santos. Influence of $\mathrm{Cu} / \mathrm{Li}$ ratio on the microstructure evolution of bobbin-tool friction stir welded $\mathrm{Al}-\mathrm{Cu}-\mathrm{Li}$ alloys. Journal of Materials Research and Technology 8(2), 2019. DOI:10.1016/j.jmrt.2019.01.014.

[5] H.-S. Lee, J.-H. Yoon, J.-T. Yoo, K. No. Friction stir welding process of aluminum-lithium alloy 2195. Procedia Engineering 149:62 - 66, 2016. International Conference on Manufacturing Engineering and Materials, ICMEM 2016, 6-10 June 2016, Nový Smokovec, Slovakia, DOI:10.1016/j.proeng.2016.06.639

[6] Y. E. Ma, Z. Xia, R. Jiang, W. Li. Effect of welding parameters on mechanical and fatigue properties of friction stir welded 2198 T8 aluminum-lithium alloy joints. Engineering Fracture Mechanics 114:1 - 11, 2013. DOI:10.1016/j.engfracmech.2013.10.010.

[7] F. Zhang, J. Shen, X.-D. Yan, et al. Homogenization heat treatment of $2099 \mathrm{Al}-\mathrm{Li}$ alloy. Rare Metals 33(1):28-36, 2014. DOI:10.1007/s12598-013-0099-9

[8] Y. Tao, D. Ni, B. Xiao, et al. Origin of unusual fracture in stirred zone for friction stir welded 2198-T8 Al-Li alloy joints. Materials Science and Engineering: A 693:1 - 13, 2017. DOI:10.1016/j.msea.2017.03.079

[9] C. Gao, R. Gao, Y. Ma. Microstructure and mechanical properties of friction spot welding aluminium-lithium 2A97 alloy. Materials \& Design 83:719 - 727, 2015. DOI:10.1016/j.matdes.2015.06.013.

[10] R. Rajan, P. Kah, B. Mvola, J. Martikainen. Trends in aluminium alloy development and their joining methods. Reviews on Advanced Materials Science 44:383-397, 2016.
[11] T. Dursun, C. Soutis. Recent developments in advanced aircraft aluminium alloys. Materials $\&$ Design $\mathbf{5 6 : 8 6 2 ~ - ~ 8 7 1 , ~ 2 0 1 4 . ~ D O I : 1 0 . 1 0 1 6 / j . m a t d e s . 2 0 1 3 . 1 2 . 0 0 2 ~}$

[12] B. Han, W. Tao, Y. Chen, H. Li. Double-sided laser beam welded T-joints for aluminum-lithium alloy aircraft fuselage panels: Effects of filler elements on microstructure and mechanical properties. Optics $\&$ Laser Technology 93:99 - 108, 2017. DOI:10.1016/j.optlastec.2017.02.004

[13] G. Wang, Y. Zhao, Y. Hao. Friction stir welding of high-strength aerospace aluminum alloy and application in rocket tank manufacturing. Journal of Materials Science ES Technology 34(1):73 - 91, 2018. DOI:10.1016/j.jmst.2017.11.041.

[14] M. X. Milagre, N. V. Mogili, U. Donatus, et al. On the microstructure characterization of the AA2098-T351 alloy welded by FSW. Materials Characterization 140:233 - 246, 2018. DOI:10.1016/j.matchar.2018.04.015

[15] W. Li, Q. Chu, X. Yang, et al. Microstructure and morphology evolution of probeless friction stir spot welded joints of aluminum alloy. Journal of Materials Processing Technology 252:69 - 80, 2018. DOI:10.1016/j.jmatprotec.2017.09.003.

[16] C. C. de Castro, A. H. Plaine, G. P. Dias, et al. Investigation of geometrical features on mechanical properties of AA2198 refill friction stir spot welds. Journal of Manufacturing Processes 36:330 - 339, 2018. DOI:10.1016/j.jmapro.2018.10.027

[17] O. Hatamleh, I. V. Rivero, S. E. Swain. An investigation of the residual stress characterization and relaxation in peened friction stir welded aluminum-lithium alloy joints. Materials 65 Design 30(9):3367 - 3373, 2009. DOI:10.1016/j.matdes.2009.03.038

[18] B. Han, Y. Chen, W. Tao, et al. Nano-indentation investigation on the local softening of equiaxed zone in 2060-T8/2099-T83 aluminum-lithium alloys T-joints welded by double-sided laser beam welding. Journal of Alloys and Compounds 756:145 - 162, 2018. DOI:10.1016/j.jallcom.2018.05.014.

[19] B. Han, Y. Chen, W. Tao, et al. Microstructural evolution and interfacial crack corrosion behavior of double-sided laser beam welded 2060/2099 Al-Li alloys T-joints. Materials \& Design 135:353 - 365, 2017. DOI:10.1016/j.matdes.2017.09.042

[20] X. Chen, Z. Lei, Y. Chen, et al. Nano-indentation and in-situ investigations of double-sided laser beam welded 2060-T8/2099-T83 Al-Li alloys T-joints. Materials Science and Engineering: A 756:291 - 301, 2019. DOI:10.1016/j.msea.2019.04.066

[21] B. Fu, G. Qin, X. Meng, et al. Microstructure and mechanical properties of newly developed aluminum-lithium alloy 2A97 welded by fiber laser. Materials Science and Engineering: A 617:1 - 11, 2014. DOI:10.1016/j.msea.2014.08.038.

[22] X. Zhang, W. Yang, R. Xiao. Microstructure and mechanical properties of laser beam welded Al-Li alloy 2060 with Al-Mg filler wire. Materials \& Design 88:446 - 450, 2015. DOI:10.1016/j.matdes.2015.08.144 